\title{
Stereotactic aspiration for hypertensive intracerebral haemorrhage in a Chinese population: a retrospective cohort study
}

To cite: Zhang $X$, Zhou S, Zhang $Q$, et al. Stereotactic aspiration for hypertensive intracerebral haemorrhage in a Chinese population: a retrospective cohort study. Stroke and Vascular Neurology 2019;4: e000200. doi:10.1136/ svn-2018-000200

Received 24 0ctober 2018 Revised 9 February 2019 Accepted 13 February 2019 Published Online First 2 March 2019

\section{Check for updates}

(c) Author(s) (or their employer(s)) 2019. Re-use permitted under CC BY-NC. No commercial re-use. See rights and permissions. Published by BMJ.

${ }^{1}$ Department of Neurosurgery, The Fifth Affiliated Hospital of Zhengzhou University, Zhengzhou, China

${ }^{2}$ Department of Radiation Oncology and Comprehensive Cancer Center, The University of Michigan, Ann Arbor, Michigan, USA

${ }^{3}$ Department of Neurosurgery, Neihuang People's Hospital, Neihuang, China

Correspondence to Ph.D;M.D Xinjun Wang; wangxj@zzu.edu.cn

\section{ABSTRACT}

Objective We aimed to compare the therapeutic effects of stereotactic aspiration and best medical management in patients who developed supratentorial hypertensive intracerebral haemorrhage ( $\mathrm{HICH}$ ) with a volume of haemorrhage between 20 and $40 \mathrm{~mL}$.

Methods The clinical data of 220 patients with supratentorial $\mathrm{HICH}$ with a volume between 20 and $40 \mathrm{~mL}$ were retrospectively analysed. Among them, 142 received stereotactic aspiration surgery (stereotactic aspiration group) and 78 received best medical management (conservative group). All were followed up for 6 months. Multivariate logistic regression and Kaplan-Meier survival curves were used to compare the outcome between the two groups.

Results The rebleeding rate was lower in the group that had stereotactic aspiration when compared with the group with medical treatment $\left(6[4.2 \%]\right.$ vs 9 [11.5\%], $\chi^{2}=4.364$, $\mathrm{p}=0.037$ ). After 6 months, although the mortality rate did not differ significantly between the two groups (8 cases [5.6\%] vs 10 cases [12.8\%], $\left.\chi^{2}=3.461, p=0.063\right)$, the rate of a favourable outcome was higher in the group who received stereotactic aspiration $\left(\chi^{2}=15.870, p=0.000\right)$. Logistic regression identified that medical treatment $(\mathrm{OR}=1.64, \mathrm{p}=0.000)$ was an independent risk factor for an unfavourable outcome. The Kaplan-Meier curves indicated that the median favourable outcome time in the stereotactic aspiration group was 59.5 days compared with that in the medically treated group (87.0 days). The log-rank test indicated that the prognosis at 6 months was better for those treated with stereotactic haematoma aspiration $\left(\chi^{2}=29.866, p=0.000\right)$. However, the 6-month survival rate was similar between the two groups $\left(\chi^{2}=3.253, p=0.068\right)$.

Conclusions Stereotactic haematoma aspiration significantly improved the quality of life, although did not effectively reduce the rate of mortality. When selected appropriately, patients with HICH may benefit from this type of surgical intervention.

\section{INTRODUCTION}

Hypertensive intracerebral haemorrhage (HICH) is the most common type of spontaneous intracerebral haemorrhage (ICH) and accounts for approximately $70 \%-80 \%$ of all ICHs. ${ }^{1}$ The mechanical impact of early haemorrhage and direct compression by the haematoma inside the brain parenchyma cause direct brain injury. Later inflammatory reaction destroys the blood-brain barrier (BBB) and leads to secondary brain injury. ${ }^{2}$

The current guidelines for the treatment of ICH in the USA and Europe have no specific recommendations on surgical interventions. ${ }^{34}$ For supratentorial ICH, the Chinese guideline recommended surgical treatment if the following criteria are met: haemorrhage volume $>30 \mathrm{~mL}$, midline shift $>0.5 \mathrm{~cm}$ and obvious compression of the lateral ventricles. For some, individualised treatment should be considered if the volume of haemorrhage is $<30 \mathrm{~mL} .{ }^{35}$ Previous studies have shown that both surgical evacuation of a haematoma and conservative therapy were the mainstay treatments for ICH. $^{6}$ Several prospective randomised controlled trials (RCTs) in the past four decades have mostly failed to demonstrate any improvement of outcome in surgically treated patients. ${ }^{7-10}$ The surgical treatment for intracerebral hemorrhage (STICH) trial concluded that there was no significant benefit from the conventional aggressive surgical treatment over conservative medical treatment in patients with ICH. ${ }^{1011}$

However, the prognosis of patient with ICH was related to the volume and severity of a haemorrhage volume. Patients with ICH with a huge haematoma volume have an unsatisfactory prognosis after surgical treatment because of significant brain injury. Compared with conservative treatment, surgical treatment could offer immediate relief of the pressure effect of a large haematoma in patients with ICH with a larger or widespread haemorrhage volume. In contrast, the trauma associated with surgical treatment may outweigh the benefit in ICH patients with a small haemorrhage volume. Therefore, the volume of haemorrhage should be carefully categorised when determining the optimal treatment options. Currently, for patients with supratentorial ICH, there are no clear haematoma 
volume criteria that would guide the selection of treatment plan. ${ }^{1213}$

In recent years, the minimally invasive stereotactic aspiration has been validated to be a promising neurosurgical alternative to treat $\mathrm{ICH} .{ }^{12}$ The minimally invasive surgery plus alteplase in intracerebral haemorrhage evacuation (MISTIE II) trial showed improved efficacy of stereotactic aspiration in patients with ICH. ${ }^{13}$ Both stereotactic aspiration and medical therapy are treatment options for patients with supratentorial ICH with a volume $<40 \mathrm{~mL}{ }^{3}$ However, there are no clear criteria on which one should be the preferred treatment currently. In this study we retrospectively analysed the outcome of stereotactic haematoma aspiration for patients with supratentorial $\mathrm{HICH}$ and the haematoma volume ranged from 20 to $40 \mathrm{~mL}$.

\section{MATERIALS AND METHODS \\ Patients}

The clinical data of all patients with ICH admitted from January 2013 to January 2018 were collected retrospectively. Based on the admitting CT scan, the volume of the ICH in millilitres was estimated based on its approximate elliptical volume using the $\mathrm{ABC} / 2$ formula, or $\mathrm{ABC} / 3$ formula for those with ICH of irregular shapes. ${ }^{14} 15$

\section{Inclusion and exclusion criteria for patients}

Patients included in the analysis must meet the following inclusion criteria: age between 18 and 75 years; diagnosis of supratentorial ICH based on the CT scan; haemorrhage volume between 20 and $40 \mathrm{~mL}$; history of a diagnosis of hypertension; onset within 24 hours accompanied by varying degrees of neurological dysfunction, including headache and limb hemiplegia; signed informed consent; and being followed up for at least 6 months.

Patients with ICH were excluded based on the following exclusion criteria: not an $\mathrm{HICH}$ (eg, arteriovenous malformation, aneurysm, amyloidosis, moyamoya disease, brain parasite or tumour-related stroke); traumatic intracranial haemorrhage; coagulopathy and the international normalised ratio (INR) was $>1.5^{13} 16$; other serious systemic diseases; or missing follow-up data.

\section{Data collected and analysed}

The following data were collected and analysed: history of stroke, hyperlipidaemia, diabetes, cardiovascular comorbidity, nicotine and alcohol abuse, imaging findings, Glasgow Coma Scale (GCS) score, blood pressure, haematoma volume, laboratory values, time of onset of symptom to admission, any diagnoses of pneumonia, hypoalbuminaemia, urinary tract infection, sepsis and multiple-organ dysfunction syndrome (MODS). ${ }^{17-19}$

\section{Treatment methods}

All operations were performed under local anaesthesia and intravenous sedation. A stereotactic frame (Leksell, Elekta, Stockholm, Sweden) was used to guide the operation. The target points were first defined at the level of the largest expansion of the haematoma based on the CT scan. The precise frame parameter of the stereotactic instrument corresponding to the puncture target was obtained and corrected simultaneously. The best puncture points were determined according to the target area. An area of the scalp of 3-4 cm was cut, a skull retractor was fixed and the skull drilled while maintaining haemostasis using the bone wax. A cross-shaped incision was made in the dura mater along with electrocoagulation of the superficial cortex. The guide was installed while paying special attention to avoid injury to the important functional areas and the main blood vessels. The catheter tip was advanced to a predetermined depth, the core of the probe was then removed, and the haematoma was gently aspirated out using a syringe until one-third of it had been removed (dilution by saline solution if the blood was thick) without applying excessive pressure. A needle-like haematoma disintegrator was inserted. When no more blood could be aspirated out, the haematoma cavity was thoroughly rinsed with saline until the solution was clear.

Postoperative CT scans were obtained 24 hours after surgery to evaluate the position of the catheter, the drainage of the haematoma and the residual haematoma volume. If the puncturing needle had been placed in the centre of the haematoma and was stable without rebleeding, the drainage bag positioned $10 \mathrm{~cm}$ above the head was linked to the draining catheter and switched on to allow drainage. Based on the residual haematoma volume as determined by the CT scan, urokinase $\left(1.0 \times 10^{4} \mathrm{IU}\right.$; NDPharm, Nanjing, Jiangsu, China) was dissolved in $3 \mathrm{~mL}$ of saline and injected into the haematoma cavity. Two to fourhours later, the incision was drained. This procedure was performed two or three times per day for 2-4 days. The time of extubation was determined based on the volume of drainage, the colour of the drainage fluid and the condition on the repeated CT. The drainage tube was generally retained for $2-7$ days.

In the best medical management group, the blood pressure was stabilised to less than $140 \mathrm{~mm} \mathrm{Hg}$ within 1 hour of onset. ${ }^{2021}$

Both groups of patients also received the best medical treatment and early rehabilitation. All patients underwent CT scan on admission, and on days 1 and 3. A patient may have more CT if clinically indicated. Patients who were on anticoagulants received Kcentra to keep an INR of $<1.5$. ${ }^{11} 16$ All patients received standard medical management according to the guidelines of the American Heart Association/American Stroke Association Stroke Council for the treatment of spontaneous ICH in adults. ${ }^{11}$

\section{Outcome assessment}

Two neurosurgeons ( $\mathrm{SZ}$ and $\mathrm{XF}$ ) blinded to clinical data assessed the outcome of the patients. The patients were followed up for 6 months by hospital visit, telephone call or clinic visit. The following parameters were compared between the two patient groups: rebleeding rate (intracerebral rebleeding was defined as ICH growth $>30 \%$ or 
$>6 \mathrm{~mL}$ from the baseline ICH volume ${ }^{22}$ ), 6-month mortality rate and 6-month score on the modified Rankin Scale (mRS). A favourable outcome was defined as an mRS score of $0-3$ and an unfavourable outcome as $4-6 .{ }^{23}$

\section{Statistical analysis}

Statistical analyses were performed using a standard statistical software package (SPSS V.23.0). The significance threshold was set at $\alpha=0.05$, and two-sided statistical tests were performed. Categorical variables were expressed as number (percentage) values, and they were compared using the Pearson's $\chi^{2}$ test or Fisher's exact test. The Shapiro-Wilk test was used to determine the type of distribution that the data conformed to. Data were presented as either mean $\pm \mathrm{SD}$ values (which were compared using Student's t-test) or median and IQR values (which were compared using the Mann-Whitney U test), as appropriate.

The influence of treatment on prognosis was investigated using multivariate logistic regression. All multivariate regression analyses were repeated by including all of the variables if $\mathrm{p}<0.1$ was achieved in the univariate analysis.

In order to further verify the relationship between treatment modality and outcome, Kaplan-Meier survival curves were done and comparisons were performed using the log-rank test. Survival time was defined as the time from onset to a favourable outcome (in days). Outcome was dichotomised into unfavourable outcome (censored) and favourable outcome according to the survival of patients.

Table 1 Demographics and baseline data of patients in the stereotactic haematoma aspiration and best medical management group

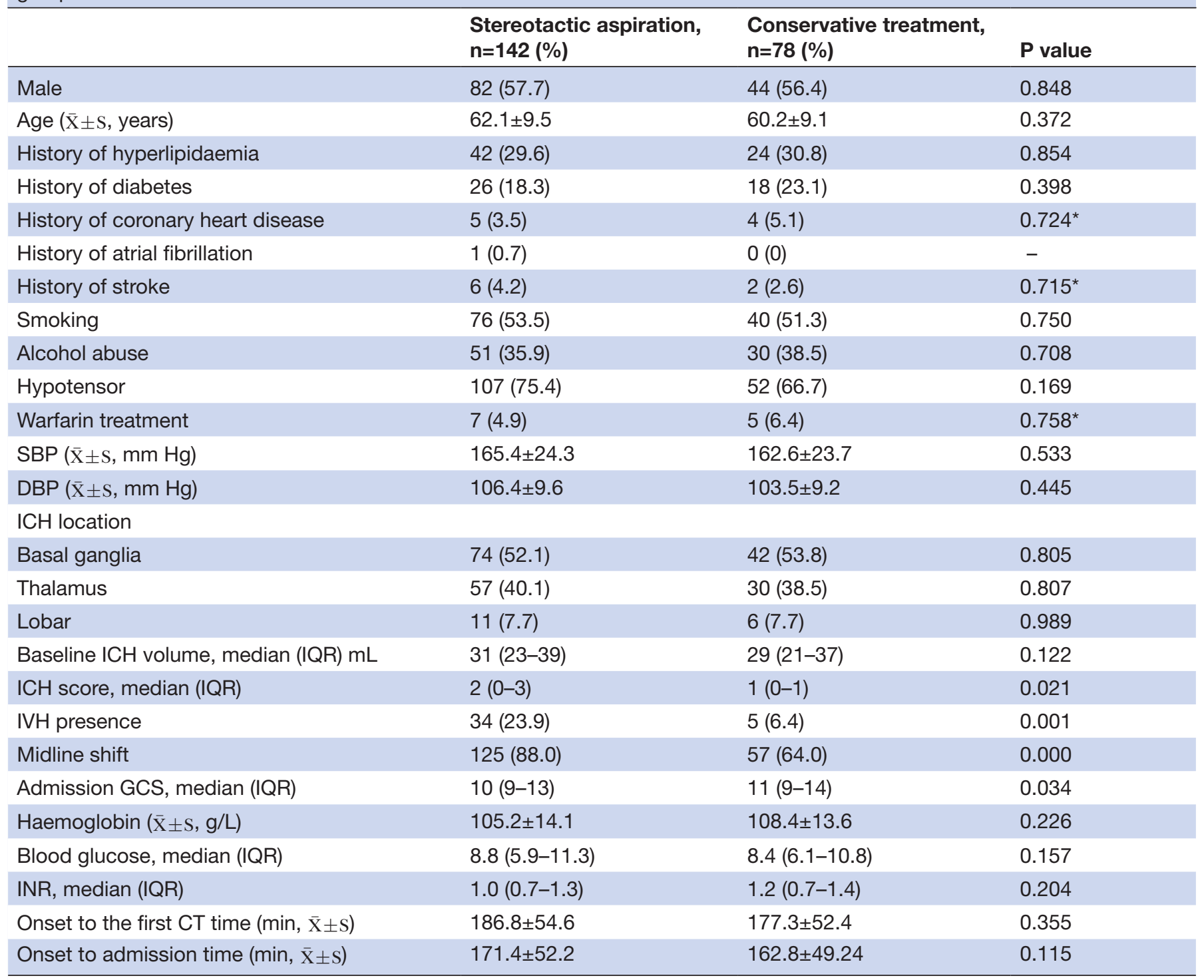

*Fisher's exact test.

DBP, diastolic blood pressure, $1 \mathrm{~mm} \mathrm{Hg}=0.133 \mathrm{kPa}$; GCS, Glasgow Coma Scale; ICH, intracerebral haemorrhage; INR, International normalised ratio; IVH, intraventricular haemorrhage; SBP, systolic blood pressure. 

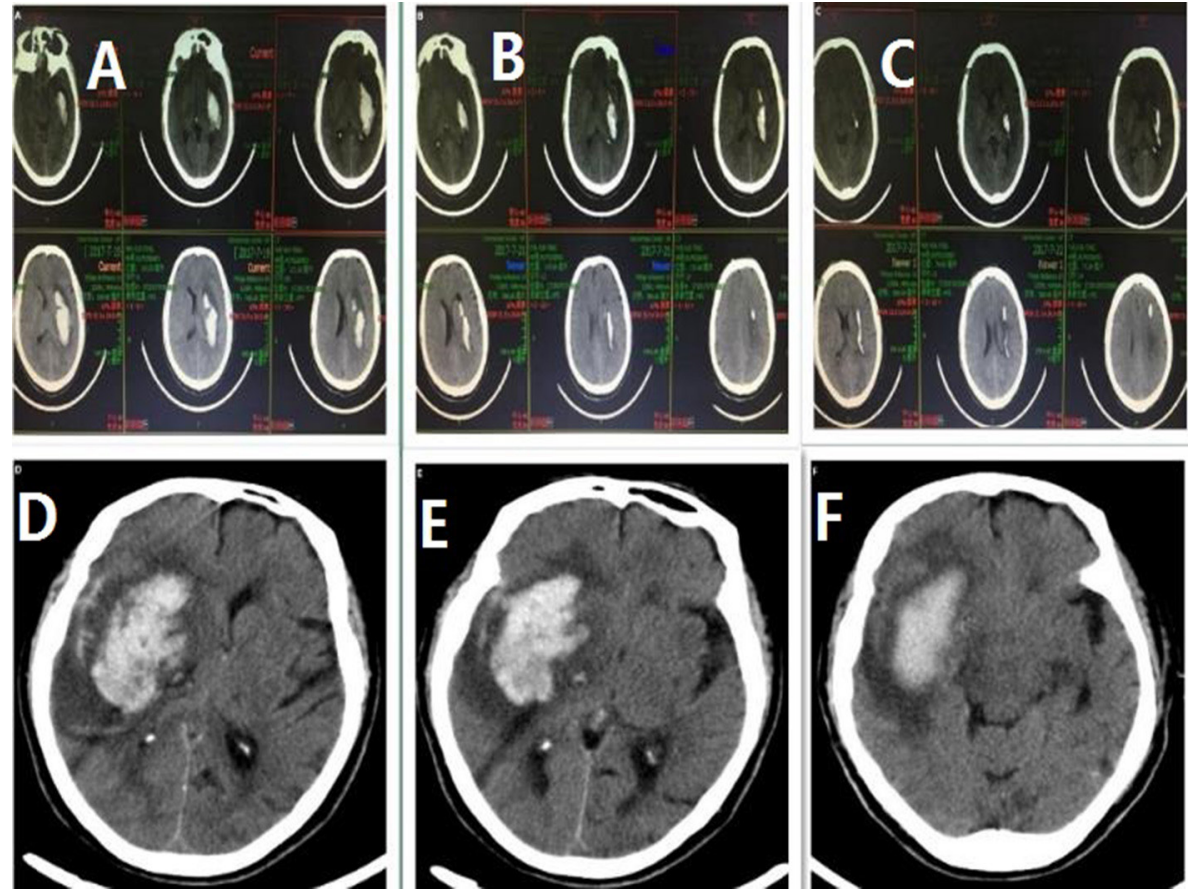

Figure 1 (A) CT scans of one patient on admission, (B) CT scans of the same patient after completing stereotactic aspiration with urokinase (lower) after 2 days and (C) CT scans of the same patient after completing stereotactic aspiration with urokinase (lower) after 3 days. (D) CT scans of another patient who received conservative treatment on admission, (E) CT scans of the same patient after 3 days and (F) CT scans of the same patient after 9 days.

\section{RESULTS}

This study included 452 cases of ICH. Among them, 56 had infratentorial haemorrhage, 98 had a haematoma volume of $>40 \mathrm{~mL}$ (with 3 cases of aneurysm rupture), 16 had a haematoma volume of $<20 \mathrm{~mL}$ (with 11 cases of traumatic bleeding and 2 of intracranial diffuse haemorrhage), 6 were tumour-related, 5 were related to moyamoya (with 2 cases of a haemorrhage volume $>40 \mathrm{~mL}$ ), 4 had renal failure (age $>75$ years), 2 had heart failure (New York Heart Association class IV), 4 had amyloidosis, 2 had arteriovenous malformation bleeding, 26 had elevated INR $\geq 1.5$ and 15 lost to follow-up. After excluding these 232 patients, the final 220 patients were included in the final analysis.

Of 220 patients entered into the final analysis, their average age was $60.4 \pm 9.2$ years (range: $33-74$ years), with a median baseline ICH volume of $30 \mathrm{~mL}$ (IQR: 21-39 mL). Their median admission GCS score was 11 (IQR: 9-14). Those with an ICH volume $\geq 30 \mathrm{~mL} \quad(\mathrm{n}=130)$ had surgical indications, but 44 of them refused the surgery. Ninety patients (with haematoma volumes between 20 and $30 \mathrm{~mL}$ ) progressively deteriorated, and the family members of 56 of them requested surgical treatment. Finally, 142 patients gave consent and received stereotactic haematoma aspiration $(64.5 \%)$ and 78 patients received the best medical treatment $(35.5 \%)$.

Demographic and clinical data of patients in the stereotactic aspiration and conservative groups

Rates of intraventricular haemorrhage (IVH), brain midline shifts and ICH score were higher, and the GCS score was lower on admission in patients in the stereotactic aspiration group than those in the best medical management group (all $\mathrm{p}<0.05$; table 1 ).

\section{Effects of stereotactic haematoma aspiration and best medical management on outcome \\ Secondary outcomes}

No case of intracranial infection occurred in either group. The rebleeding rate was significantly lower in patients who received stereotactic aspiration (6 cases, $4.2 \%)$ than those in the best medical management group ( 9 cases, $11.5 \% ; \chi^{2}=4.364, p=0.037$ ). In the surgical group, six cases of rebleeding had enlargement of haematoma in the right basal ganglia. Among them, three cases had blood pressure fluctuation. Follow-up CT of the head showed improvement (6-12 mL) without further expansion. Follow-up CT in three patients also showed an island or spot sign that led to subsequent enlargement. These patients had emergency craniotomy under microscopic guidance with haematoma removal and decompression of the bone flap.

In the best medical management group, eight cases had minimal haematoma enlargement $(6-10 \mathrm{~mL})$ and their condition did not deteriorate. One had CT $>40 \mathrm{~mL}$ haematoma enlargement on follow-up CT 24 hours later associated with a spot sign. Surgical evacuation was recommended but the family refused.

Haematoma clearance was significant 3 days after stereotactic aspiration compared with the conservative group (figure 1). Patients in the stereotactic aspiration had significantly shorter hospital stay than those in 
the best medical management group $(12.1 \pm 2.6$ days vs $27.2 \pm 5.5$ days, $\mathrm{t}=8.474, \mathrm{p}<0.001)$.

\section{Primary outcomes}

In the stereotactic aspiration group, 126 patients (88.7\%) had a favourable outcome, $16(11.3 \%)$ had an unfavourable outcome and $8(5.6 \%)$ patients died (6 from pneumonia and 2 from sepsis with MODS). In the best medical management group, 52 patients $(66.7 \%)$ had a favourable outcome, $26(33.3 \%)$ had an unfavourable outcome and $10(12.8 \%)$ patients died (5 from pneumonia, 3 from refractory hypoproteinaemia with urinary tract infection and 2 from sepsis with MODS). The rate of favourable outcome was significantly higher in the stereotactic aspiration group $\left(\chi^{2}=15.870, \mathrm{p}=0.000\right)$. However, the mortality rate did not differ significantly between the two groups $\left(\chi^{2}=3.461, p=0.063\right)$.

Compared with patients with the unfavourable outcome, patients in the favourable outcome group were younger, had fewer previous strokes, had higher GCS scores on admission, had lower blood sugar levels and likely received stereotactic haematoma aspiration (all $\mathrm{p}<0.05$; table 2). Multivariate logistic regression analysis found that age $(\mathrm{OR}=1.71, \mathrm{p}=0.002)$, presence of IVH $(\mathrm{OR}=1.37, \mathrm{p}=0.014)$ and best medical management $(\mathrm{OR}=1.64, \mathrm{p}=0.000)$ were independent risk factors for an unfavourable outcome (table 3 ).

Kaplan-Meier prognostic survival curves were plotted for the two groups. The median time for a favourable outcome was 59.5 days $( \pm 3.1$ days, 95\% CI, 53.2-65.8 days) in the stereotactic aspiration group; the corresponding values in the conservative group were 87.0 days ( \pm 3.3 days, $95 \%$ CI, range $81.1-93.8$ days). The log-rank test indicated that the 6 -month prognosis was better for those who received stereotactic haematoma aspiration compared with those who had the best medical management $\left(\chi^{2}=29.866, p=0.000\right.$; figure 2$)$. The survival rate in the two groups was relatively stable after 3 months, and the log-rank test showed that there was no significant difference in mortality rate after 6 months between the two groups $\left(\chi^{2}=3.253, \mathrm{p}=0.068\right.$; figure 3$)$.

\section{DISCUSSION}

The MISTIE II and STICH trials have demonstrated that the greater reduction in the size of the haematoma, the better the patient outcome. Our study showed that patients who received surgical therapy had a significantly higher rate of favourable outcome than those receiving conservative treatment $\left(\chi^{2}=29.866, p=0.000\right)$. Comparing with the MISTIE II trial, our study treated more patients and had lower rate of rebleeding $(4.2 \%) .{ }^{13}$ The rebleeding rate was significantly lower in patients treated with stereotactic aspiration than those who had the best medical management, indicating that timely surgical treatment can control the risk of rebleeding, and reduce the chance of developing inflammatory reactions from the release of
Table 2 Demographic and baseline data of favourable and unfavourable outcome groups

\begin{tabular}{|c|c|c|c|}
\hline & $\begin{array}{l}\text { Favourable } \\
\text { outcome, } \\
\mathrm{n}=178(\%)\end{array}$ & $\begin{array}{l}\text { Unfavourable } \\
\text { outcome, } \\
\mathrm{n}=42(\%)\end{array}$ & $P$ value \\
\hline Male & $99(55.6)$ & $27(64.3)$ & 0.307 \\
\hline Age $(\overline{\mathrm{X}} \pm \mathrm{S}$, years $)$ & $56.2 \pm 8.1$ & $65.3 \pm 8.8$ & 0.000 \\
\hline $\begin{array}{l}\text { History of } \\
\text { hyperlipidaemia }\end{array}$ & $53(29.8)$ & $13(31.0)$ & 0.881 \\
\hline History of diabetes & 38 (19.3) & $15(30.6)$ & 0.084 \\
\hline $\begin{array}{l}\text { History of coronary heart } \\
\text { disease }\end{array}$ & 7 (3.9) & $2(4.8)$ & $0.682^{*}$ \\
\hline History of atrial fibrillation & $0(0)$ & $1(2.4)$ & $0.191^{*}$ \\
\hline History of stroke & $3(1.7)$ & $5(11.9)$ & $0.007^{*}$ \\
\hline Smoking & $90(50.6)$ & $26(61.9)$ & 0.185 \\
\hline Alcohol abuse & $62(34.8)$ & $19(46.3)$ & 0.169 \\
\hline Hypotension & $130(73.0)$ & $29(69.0)$ & 0.604 \\
\hline Warfarin treatment & $8(4.5)$ & $4(9.5)$ & $0.250^{*}$ \\
\hline $\operatorname{SBP}(\overline{\mathrm{X}} \pm \mathrm{S}, \mathrm{mm} \mathrm{Hg})$ & $162.9 \pm 22.8$ & $164.5 \pm 24.2$ & 0.535 \\
\hline $\mathrm{DBP}(\overline{\mathrm{X}} \pm \mathrm{S}, \mathrm{mm} \mathrm{Hg})$ & $103.7 \pm 9.1$ & $104.9 \pm 9.3$ & 0.674 \\
\hline \multicolumn{4}{|l|}{ ICH location, n (\%) } \\
\hline Basal ganglia & $95(53.4)$ & $21(50.0)$ & 0.694 \\
\hline Thalamus & 68 (38.2) & $19(45.2)$ & 0.402 \\
\hline Lobar & $15(8.4)$ & $2(4.8)$ & $0.538^{*}$ \\
\hline $\begin{array}{l}\text { Baseline ICH volume, } \\
\text { median (IQR), mL }\end{array}$ & $30(21-39)$ & $33(22-38)$ & 0.035 \\
\hline ICH score, median (IQR) & $2(0-3)$ & $2(1-3)$ & 0.316 \\
\hline IVH presence & $26(14.6)$ & $13(31.0)$ & 0.013 \\
\hline Midline shift & $145(81.5)$ & $37(88.1)$ & 0.306 \\
\hline $\begin{array}{l}\text { Admission GCS, median } \\
\text { (IQR) }\end{array}$ & $11(9-14)$ & $10(9-13)$ & 0.038 \\
\hline Haemoglobin ( $\overline{\mathrm{X}} \pm \mathrm{S}, \mathrm{g} / \mathrm{L})$ & $108.7 \pm 13.4$ & $105.3 \pm 13.2$ & 0.332 \\
\hline $\begin{array}{l}\text { Blood glucose, median } \\
\text { (IQR) }\end{array}$ & $7.4(6.2-8.7)$ & $8.9(6.8-11.2)$ & 0.027 \\
\hline INR, median (IQR) & $1.1(0.7-1.3)$ & $1.2(0.8-1.4)$ & 0.152 \\
\hline $\begin{array}{l}\text { Onset to the first CT time } \\
(\min , \bar{X} \pm S)\end{array}$ & $182.7 \pm 53.3$ & $181.8 \pm 53.4$ & 0.627 \\
\hline $\begin{array}{l}\text { Onset to admission time } \\
(\min , \overline{\mathrm{X}} \pm \mathrm{S})\end{array}$ & $165.18 \pm 51.4$ & $165.7 \pm 50.5$ & 0.884 \\
\hline Treatment plan, n (\%) & & & 0.000 \\
\hline Stereotactic aspiration & $126(88.7)$ & $16(11.3)$ & \\
\hline Conservative treatment & $52(70.8)$ & $26(38.1)$ & \\
\hline
\end{tabular}

${ }^{*}$ Fisher's exact test.

DBP, diastolic blood pressure, $1 \mathrm{~mm} \mathrm{Hg}=0.133 \mathrm{kPa}$; GCS, Glasgow Coma Scale; ICH, intracerebral haemorrhage; INR, International normalised ratio; IVH, intraventricular haemorrhage; SBP, systolic blood pressure.

interleukin (IL)-10 and other proinflammatory factors, as well as reduce the severity of destruction by haematoma. ${ }^{24}$

The haematoma clearance was significant up to 3 days after the development of ICH. By reducing the clot burden on the surrounding brain tissue and secondary injury, these patients improved their functional recovery, 
Table 3 Multivariate analysis of favourable outcome and unfavourable outcome

\begin{tabular}{llll}
\hline & OR & $\mathbf{9 5 \%}$ Cl & P value \\
\hline Age & 1.71 & 1.22 to 2.36 & 0.002 \\
IVH presence & 1.37 & 1.15 to 1.65 & 0.014 \\
Conservative treatment & 1.64 & 1.25 to 2.07 & 0.000 \\
\hline
\end{tabular}

IVH, intraventricular haemorrhage.

length of hospital stay and independent activities of daily living.

The rate of a favourable outcome after 6 monthsaccording to the mRS score-was significantly higher for those who received stereotactic haematoma aspiration $\left(\chi^{2}=15.870, p=0.000\right)$. One possible explanation of this improved functional outcome was the prevention of formation of perihaematomal oedema (PHE) early on. PHE volume could double within 3-11 days, ${ }^{25}$ and might be partially related to erythrocyte lysis and haemoglobin release. The increase of brain iron level from erythrocyte degradation increased brain water content that adversely affected the prognosis. ${ }^{26-28}$ Previous MRI studies and animal experiments have supported a vasogenic origin of PHE in ICH rather than cytotoxic oedema in ischaemia. ${ }^{29}{ }^{30}$ Surgery can relieve the space-occupying effect early, thereby reducing the secondary injury to brain tissue caused by haematoma compression, alleviating brain oedema, reducing the intracranial pressure and improving cerebral blood flow. ${ }^{31}{ }^{32}$ In contrast, if not surgically cleared, haematoma was absorbed slowly and occupied the space for a long time. The presence of a haematoma inside the brain facilitated the development

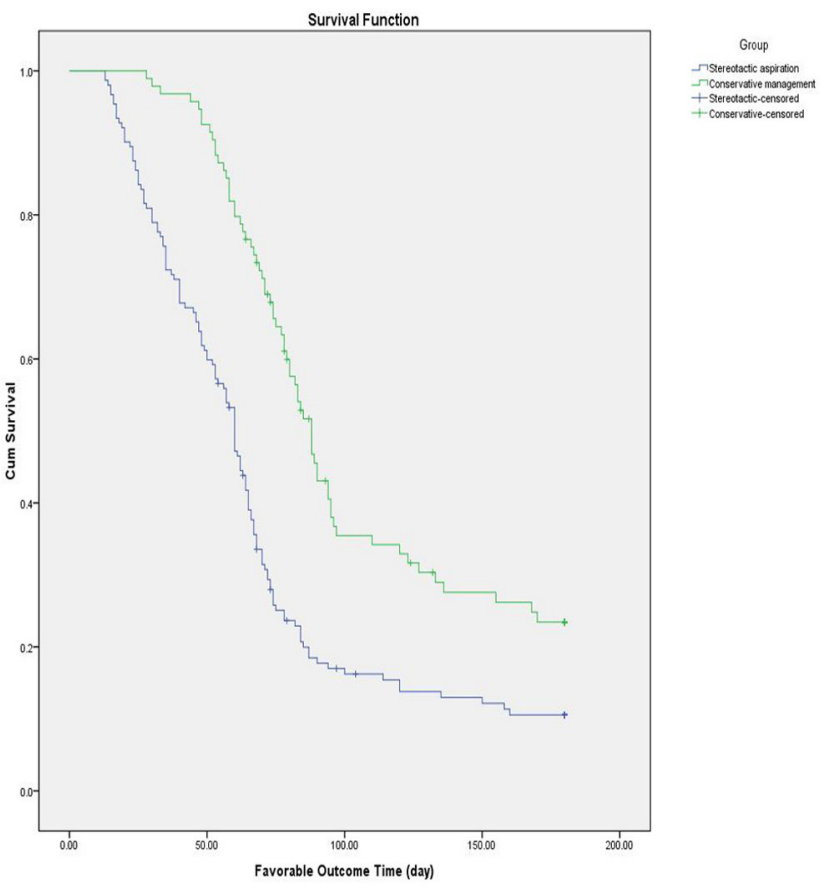

Figure 2 Kaplan-Meier curve showing the 6-month favourable outcome probability. Cum, cumulative.

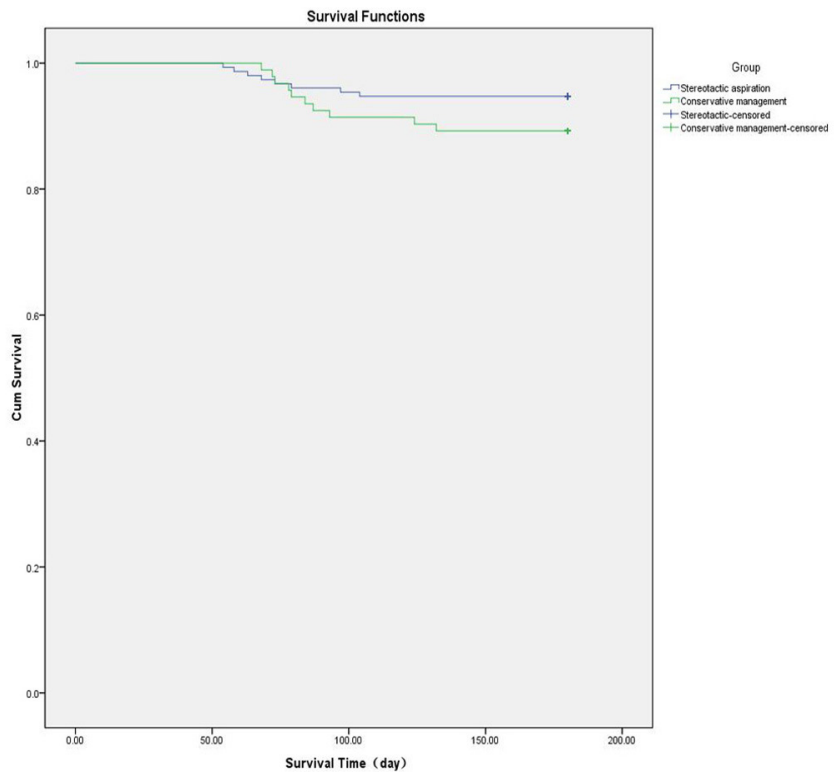

Figure 3 Kaplan-Meier curve showing the 6-month survival probability. Cum, cumulative.

of inflammatory factors such as high mobility group box 1, Toll-like receptor, receptor of advanced glycosylation end products and IL-6. The inflammatory response would destroy the BBB and the surrounding brain tissue resulting in varying degrees of cognitive dysfunction and difficulty in performing activities of daily living, ${ }^{33-35}$ as well as slow or even irreversible recovery of nerve injury.

Our study also found no difference in mortality between the two treatment groups $\left(\chi^{2}=3.461, p=0.063\right)$, a similar conclusion as in MISTIE II, but lower total mortality rate $(8.2 \%)$ than in MISTIE II $(12.5 \%) .{ }^{13}$ Such finding could be related to the patients selected for surgical treatment: small volume of haematoma and the supratentorial location. In our study, the survival curves indicated that the survival rates in the two groups were relatively stable after 3 months. The log-rank test showed no significant intergroup difference in mortality rate after 6 months $\left(\chi^{2}=3.253, p=0.068\right)$. These results demonstrated that with less haematoma volume, less space-occupying effect and stable secondary damage, patients with supratentorial haemorrhage with volumes of $20-40 \mathrm{~mL}$ could absorb the haematoma gradually even with the best medical management. Therefore surgical treatment did not significantly reduce the mortality rate.

After adjusting for confounding factors, logistic multivariate analysis showed that age $(\mathrm{OR}=1.71, \mathrm{p}=0.002), \mathrm{IVH}$ presence $(\mathrm{OR}=1.37, \mathrm{p}=0.014)$ and conservative treatment $(\mathrm{OR}=1.64, \mathrm{p}=0.000)$ remained independent risk factors for an unfavourable outcome of ICH. Being older was associated with a worse prognosis due to impaired immunity, resulting in a higher probability of complications such as pneumonia, hypoproteinaemia, sepsis and urinary tract infection. ${ }^{36}$ In line with previous studies, IVH is actually a risk factor of poor prognosis. ${ }^{3738}$ 
The MISTIE II trial proved minimally invasive surgery plus alteplase was safe, with a possible advantage of better functional outcome at 180 days than with standard medical care. ${ }^{13}$ In our study, urokinase was used and demonstrated the similar outcome. Our study was the first to demonstrate that urokinase could be a safe and effective alternative to alteplase and cheaper in this indication.

Stereotactic haematoma aspiration is a mature technique. Compared with traditional craniotomy, it is less invasive, does not require general anaesthesia and the impact of surgical trauma is less. Patients with $\mathrm{HICH}$ are generally older, often have varying degrees of brain atrophy and a poor tolerance of surgical trauma or related haemorrhage and other perioperative adverse events. Despite no significant change in mortality, a low rate of rebleeding, rapid clearance of haematoma, shorter hospital stays and favourable functional recovery have been clearly demonstrated with the surgical treatment. Our study was completed prior to the announcement of the MISTIE III trial, and methodologically there were differences. Hence, the significance may be small if including the discussion on MISTIE III.

There are some limitations to our study. First, this was a retrospective analysis, and possible changes of the patient conditions might not be accurately recorded on time. Second, despite consideration of confounding factors, this was not a clinical RCT. Third, this study only reviewed the effect of treatment on prognosis for haemorrhage volumes in the range of $20-40 \mathrm{~mL}$. Future studies should attempt to determine the treatment options for other haemorrhage volumes and also analyse data from multiple centres.

\section{CONCLUSION}

Although without significant difference in mortality, in patients who developed HICH with a volume of haematoma between 20 and $40 \mathrm{~mL}$, surgical evacuation of haematoma was superior to the best medical management in terms of reducing recurrence of bleeding, shortening length of stay and improving functional recovery. More clinical trials are need to explore the opportunity to further reduce mortality in this patient population and improve outcome in those with larger haematoma volume.

Contributors XZ was involved in drafting the work. XW was responsible for revising the manuscript critically for important intellectual content. $S Z$ and QZ contributed to the conception or design of the work. XF, YW, JL, BL and ZY contributed to the acquisition and analysis of data for the work.

Funding This study was supported by awards from the Science and Technology Department (Henan Province, China: 182102310158) and Education Department of Henan Province, China (201503135).

Competing interests None declared.

Patient consent for publication Obtained.

Ethics approval This study was performed in accordance with the ethical standards laid down in the 1964 Declaration of Helsinki and its later amendments. All procedures performed in the study were approved by the Institutional Investigational Review Board at the Fifth Affiliated Hospital of Zhengzhou University (reference number 201806).
Provenance and peer review Not commissioned; externally peer reviewed. Data sharing statement No additional data are available.

Open access This is an open access article distributed in accordance with the Creative Commons Attribution Non Commercial (CC BY-NC 4.0) license, which permits others to distribute, remix, adapt, build upon this work non-commercially, and license their derivative works on different terms, provided the original work is properly cited, appropriate credit is given, any changes made indicated, and the use is non-commercial. See: http://creativecommons.org/licenses/by-nc/4.0/.

\section{REFERENCES}

1. Meretoja A, Strbian D, Putaala J, et al. SMASH-U: a proposal for etiologic classification of intracerebral hemorrhage. Stroke 2012;43:2592-7.

2. Hammond MD, Taylor RA, Mullen MT, et al. CCR2+ Ly6C(hi) inflammatory monocyte recruitment exacerbates acute disability following intracerebral hemorrhage. J Neurosci 2014;34:3901-9.

3. Claude H J, Greenberg SM, Anderson CS, et al. Mitchell PH: Guidelines for the Management of Spontaneous Intracerebral Hemorrhage: A Guideline for Healthcare Professionals From the American Heart Association/American Stroke Association. Stroke 20152032:46.

4. Steiner T, Al-Shahi Salman R, Beer R, et al. European Stroke Organisation (ESO) guidelines for the management of spontaneous intracerebral hemorrhage. Int J Stroke 2014;9:840-55.

5. Julian S, Terbrugge KG, Mona M, et al. Michael T: A discriminative prediction model of neurological outcome for patients undergoing surgery of brain arteriovenous malformations. Stroke 2006;37:1457-64.

6. Mendelow AD, Gregson BA, Rowan EN, et al. Early surgery versus initial conservative treatment in patients with spontaneous supratentorial lobar intracerebral haematomas (STICH II): a randomised trial. The Lancet 2013;382:397-408.

7. Auer LM, Deinsberger W, Niederkorn K, et al. Körner E: Endoscopic surgery versus medical treatment for spontaneous intracerebral hematoma: a randomized study. Journal of Neurosurgery 1989;70:530

8. Morgenstern LB, Frankowski RF, Shedden P, et al. Surgical treatment for intracerebral hemorrhage (STICH): A single-center, randomized clinical trial. Neurology 1998;51:1359-.

9. Teernstra OP, Evers SM, Lodder J, et al. Stereotactic treatment of intracerebral hematoma by means of a plasminogen activator: a multicenter randomized controlled trial (SICHPA). Stroke 2003;34:968-74.

10. Mendelow AD, Gregson BA, Fernandes HM, et al. Early surgery versus initial conservative treatment in patients with spontaneous supratentorial intracerebral haematomas in the International Surgical Trial in Intracerebral Haemorrhage (STICH): a randomised trial. Lancet 2005;365:387-97.

11. Morgenstern LB, Hemphill JC, Anderson C, et al. Messé SR: Guidelines for the Management of Spontaneous Intracerebral Hemorrhage A Guideline for Healthcare Professionals From the American Heart Association/American Stroke Association. Stroke 20152032:46.

12. Staykov D, Huttner HB, Köhrmann M, et al. Novel Approaches to the Treatment of Intracerebral Haemorrhage. International Journal of Stroke 2010;5:457-65.

13. Hanley DF, Thompson RE, Muschelli J, et al. Safety and efficacy of minimally invasive surgery plus alteplase in intracerebral haemorrhage evacuation (MISTIE): a randomised, controlled, openlabel, phase 2 trial. Lancet Neurol 2016;15:1228-37.

14. Kothari RU, Brott T, Broderick JP, et al. The ABCs of measuring intracerebral hemorrhage volumes. Stroke 1996;27:1304-5.

15. Brott T, Broderick J, Kothari R, et al. Early hemorrhage growth in patients with intracerebral hemorrhage. Stroke 1997;28:1-5.

16. Frontera JA, Lewin III JJ, Rabinstein AA, et al. Guideline for reversal of antithrombotics in intracranial hemorrhage. Neurocrit Care 2016;24:6-46.

17. Tejerina E, Esteban A, Fernández-Segoviano P, et al. Accuracy of clinical definitions of ventilator-associated pneumonia: comparison with autopsy findings. J Crit Care 2010;25:62-8.

18. Muckart DJ, Bhagwanjee S. American College of Chest Physicians/ Society of Critical Care Medicine Consensus Conference definitions of the systemic inflammatory response syndrome and allied disorders in relation to critically injured patients. Crit Care Med 1997;25:1789-95.

19. Johnson JR. Wilson ML: Laboratory Diagnosis of Urinary Tract Infections in Adult Patients [with Reply]. Clinical Infectious Diseases 
An Official Publication of the Infectious Diseases Society of America 2004:39:873-4.

20. Morotti A, Marini S, Lena UK, et al. Significance of admission hypoalbuminemia in acute intracerebral hemorrhage. J Neurol 2017;264:905-11.

21. Qureshi Al. The importance of acute hypertensive response in $\mathrm{ICH}$. Stroke 2013;44:S67-S69.

22. Morotti A, Phuah CL, Anderson CD, et al. Leukocyte count and intracerebral hemorrhage expansion. Stroke 2016;47:1473-8.

23. Giede-Jeppe A, Bobinger T, Gerner ST, et al. Lymphocytopenia is an independent predictor of unfavorable functional outcome in spontaneous intracerebral hemorrhage. Stroke 2016;47:1239-46.

24. Wang KW, Cho CL, Chen HJ, et al. Molecular biomarker of inflammatory response is associated with rebleeding in spontaneous intracerebral hemorrhage. Eur Neurol 2011:66:322-7.

25. Staykov D, Wagner I, Volbers B, et al. Natural course of perihemorrhagic edema after intracerebral hemorrhage. Stroke 2011:42:2625-9.

26. Urday S, Beslow LA, Dai F, et al. Rate of Perihematomal Edema Expansion Predicts Outcome After Intracerebral Hemorrhage. Crit Care Med 2016;44:790.

27. Appelboom G, Bruce SS, Hickman ZL, et al. Volume-dependent effect of perihaematomal oedema on outcome for spontaneous intracerebral haemorrhages. J Neurol Neurosurg Psychiatry 2013;84:488-93.

28. Wu TY, Sharma G, Strbian D, et al. Natural History of Perihematomal Edema and Impact on Outcome After Intracerebral Hemorrhage. Stroke 2017;48:873.

29. McCourt R, Gould B, Kate M, et al. Blood-brain barrier compromise does not predict perihematoma edema growth in intracerebral hemorrhage. Stroke 2015;46:954-60.
30. Butcher KS, Baird T, MacGregor L, et al. Perihematomal edema in primary intracerebral hemorrhage is plasma derived. Stroke 2004;35:1879-85.

31. Veit R, Ina R, Ruth T, et al. Müller HD: Fibrinolysis therapy achieved with tissue plasminogen activator and aspiration of the liquefied clot after experimental intracerebral hemorrhage: rapid reduction in hematoma volume but intensification of delayed edema formation. Journal of Neurosurgery 2002;97:954-62.

32. Ty W, Sharma G, Strbian D, et al. Meretoja A: Natural History of Perihematomal Edema and Impact on Outcome After Intracerebral Hemorrhage. Stroke 2017;48:873.

33. Li C, Peng S, Liu X, et al. Glycyrrhizin, a direct hmgb1 antagonist, ameliorates inflammatory infiltration in a model of autoimmune thyroiditis via inhibition of TLR2-HMGB1 signaling. Thyroid 2017;27:722-31.

34. Guan XF, Chen QJ, Zuo XC, et al. Contrast media-induced renal inflammation is mediated through HMGB1 and Its Receptors in Human Tubular Cells. DNA Cell Biol 2017;36:67-76.

35. Gąsiorowski K, Brokos B, Echeverria V, et al. RAGE-TLR Crosstalk sustains chronic inflammation in neurodegeneration. Mol Neurobiol 2018;55:1-14.

36. Qureshi Al, Palesch YY, Barsan WG, et al. Intensive blood-pressure lowering in patients with acute cerebral hemorrhage. N Engl J Med Overseas Ed 2016;375:1033-43.

37. Hemphill JC, Bonovich DC, Besmertis L, et al. Johnston SC: The ICH Score. Stroke 2001;32:891.

38. Murthy SB, Moradiya Y, Shah J, et al. Nosocomial infections and outcomes after intracerebral hemorrhage: A population-based study. Neurocrit Care 2016;25:178-84. 